\title{
PSYCHE
}

\begin{tabular}{lll}
\hline Vol. 75 & September, I968 & No. 3 \\
\hline
\end{tabular}

\section{THE DEFENSIVE BEHAVIOR OF \\ PTERINOXYLUS SPINULOSUS REDTENBACHER, A WINGED STICK INSECT \\ FROM PANAMA (PHASMATODEA)*}

By Michael H. Robinson

Smithsonian Tropical Research Institute,

P. O. Box 2072, Balboa, Canal Zone.

At least two fundamental categories of anti-predator adaptations can usefully be recognized (Robinson I968). There are those adaptations which lower the probability of a predator initiating a prey capture attempt, either by concealing the presence of a potential prey (crypsis), or by advertizing its real or apparent unsuitability as a prey item (aposematism and pseudaposematism). In the second category are those devices which lower the probability that a prey capture attempt will be successful once it has been initiated. This category includes systems of active escape by flight, jumping or dropping and systems of predator deterrence by startle displays, bluffing displays, repugnatorial secretion and active counterattack. This present paper is one of a series on phasmid defensive behavior and describes anti-predator adaptations which belong to both the functional categories outlined above. The winged stick insect Pterinoxylus spinulosus is of more than usual interest since it has a resting attitude which is considerably more complex than any so far described for a stick-mimicking phasmid. This involves special attitudes of the intermediate and posterior limbs in addition to the anterior limb attitude which is associated with stick-mimicry in this and other phasmids. Both sexes display as adults but there is strong sexual dimorphism in the type of display and that of the female sex includes a stridulatory component. Both the complex resting attitude and the dimorphism of the display raise questions of considerable evolutionary interest; these are discussed below (pages 202-205).

The Neotropical phasmid genus Pterinoxylus is, according to Rehn (1957), a relatively rare one. P. spinulosus was described by Red-

*:Manuscript received by the editor May 13, 1968 
tenbacher (1908) from a single adult male and an immature female. The first adult female was described in 1957 by Rehn (loc cit). $P$. spinulosus is quite strongly sexually dimorphic. Adult males (Figures I and 2) are relatively thin and have well developed wings, whereas adult females (Figure 3) are much more robust, longer, and have reduced wings. Both sexes vary somewhat in ground color from light grey-brown to dead-leaf brown. In individual females the ground color may be interrupted by areas of pale lichenose coloration. The tegmina and the dorsal surface of the costal areas of the wings are concolorous with the body surface.

\section{Materials AND Methods}

Two male and three female adult $P$. spinulosus were collected in the laboratory clearing on Barro Colorado Island, Canal Zone, Panama during July and August 1967. A further two females were collected in February 1968 and these proved to be last instar nymphs which successfully metamorphosed into adults whilst in captivity. All the insects were successfully maintained in culture on a diet of guava (Psidium sp.) leaves, provided on short stems which were renewed twice weekly. Screen cages of one cubic meter proved satisfactory for the maintenance of these insects. The 1967 insects lived for over four months in these conditions; during this time mating was observed twice and a large number of eggs were laid. At the time of writing (April I968) the 1968 individuals are still flourishing and nymphs from the 1967 eggs have reached the fourth instar.

Details of the various elements of defensive behavior were observed both in the laboratory and under more natural conditions when the insects were placed in appropriate vegetation out of doors. The resting attitude and displays were photographed and filmed and the accompanying illustrations are based on $35 \mathrm{~mm}$ color transparencies or single frames of $16 \mathrm{~mm}$ movie film. The stridulation of the adult female was recorded on tape by my colleague Dr. A. S. Rand and the accompanying sonograms were produced from this recording through the cooperation of Dr. W. John Smith of the University of Pennsylvania.

\section{Elements of Defensive Behavior}

\section{CONCEALMENT.}

The contribution of behavior to the concealment of stick and leaf mimicking insects is usually two-fold. The animal may adopt special attitudes when at rest or in response to stimuli which could signal 
the presence of a predator and these may enhance the resemblance to the object mimicked. In addition, the animal may suppress movements which could attract the attention of predators either by being nocturnally active or by "freezing" in response to disturbance. $P$. spinulosus is active at night and assumes a resting attitude by day at all stages of development. Most stick mimicking phasmids protract the anterior limbs, side by side, in line with the long axis, in a resting attitude which increases the apparent length of the body (See Chopard 1938 for a partial review of phasmid resting attitudes). Anterior limb protraction occurs in P. spinulosus but is accompanied by special attitudes of the intermediate and posterior legs. These are shown in Figure I. As can be seen from inset A (figure I), the tibiae and tarsi of the intermediate legs are closely apposed to the inferior surface of the femora. The apparent units so formed project at an angle above the dorsal surface of the thorax. Because of the close apposition of the tibia and tarsus to the femur, which has lobulated inferior margins, the separate elements of the folded and projecting leg are concealed. The posterior legs are held in an attitude which varies somewhat with the configuration of the substrate but project ventrally and often posteriorly (as shown in inset $B$, Figure I.). The relatively short tibiae are apposed to the inferior surface of the femora and the tarsi are placed along or around the twig.

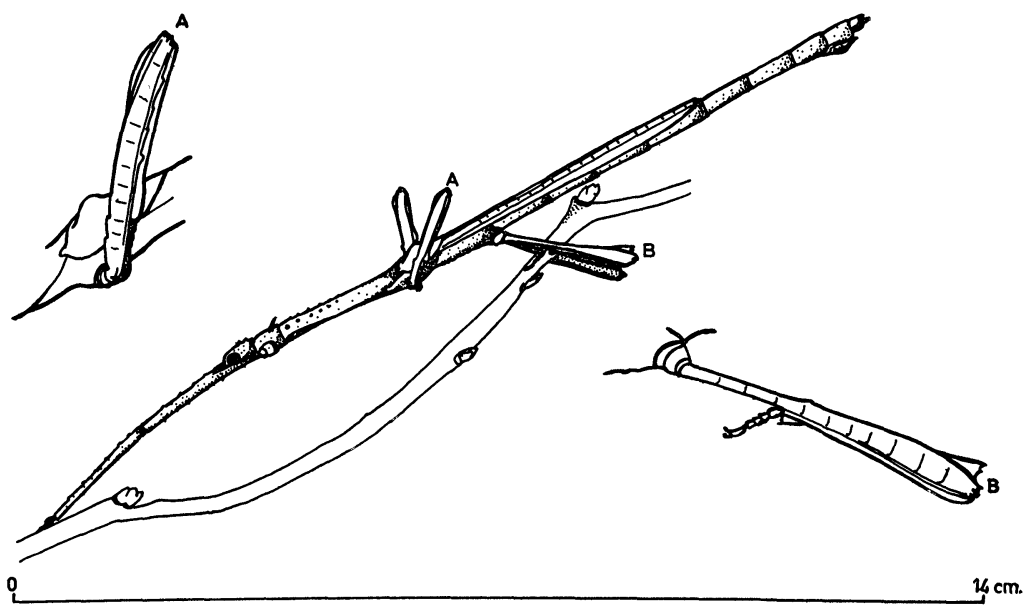

Figure 1. The resting attitude of Pterinoxylus spinulosus Redtenbacher. Note the details of the attitudes of the intermediate and posterior legs as shown in insets $A$ and $B$. (Based on a $35 \mathrm{~mm}$ color transparency). 
The resting attitude as described above was consistently assumed by adult males and maintained throughout the day unless the animals were disturbed. Adult females almost invariably adopted the described attitude as far as the intermediate limbs were concerned but apposed the posterior tibiae to the femora with less consistency. Newly hatched nymphs protracted the anterior limbs and folded the intermediate ones on assuming their first rest position. The posterior limb attitude has not been seen in nymphs up to, and including, the fourth instar although it occurs in females of the last (sixth?) nymphal instar. To the human observer, from as little as a foot away, the insect in the complete resting attitude looks remarkably like a stick with four small side shoots and details of the leg structure are indistinguishable.

\section{ACTIVE DEFENSIVE BEHAVIOR}

Escape.

Many phasmids drop or jump from the substrate in response to tactile stimulation (see, for instance, Robinson I968). This response was not induced in P. spinulosus in any circumstances.

\section{Startle Display.}

The first response to tactile stimulation ${ }^{1}$ of adults of either sex is the occurrence of wing movements whose function I interpret as anti-predator display. Males erected the wings and tegmina vertically. The wings were maintained in an erect position for upwards of one minute when, in the absence of further stimulation, they were snapped down. If the stimulus was repeated, or particularly strong, the peculiar flexure between the prothorax and mesothorax, shown in Figure 2, occurs. This gives the appearance of the insect a bizarre effect and may be maintained for some time after the wings are lowered.

Tactile stimulation of the adult female induces a sudden lateral extension of the wings beneath the raised tegmina. The main membranous area of the exposed wings is a translucent dark brown traversed by almost black radiate veins. The costal areas and the inferior surfaces of the tegmina are a conspicuous carmine. The expansion of the wings and erection of the tegmina thus reveals a strikingly colored area which is in marked contrast to the rest of the insect. In sunlight the wings produce metallic reflections. Once

\footnotetext{
${ }^{I}$ It is difficult to standardize tactile stimulation but the responses described here were consistently evoked by pinching any part of the body with the fingers or forceps.
} 


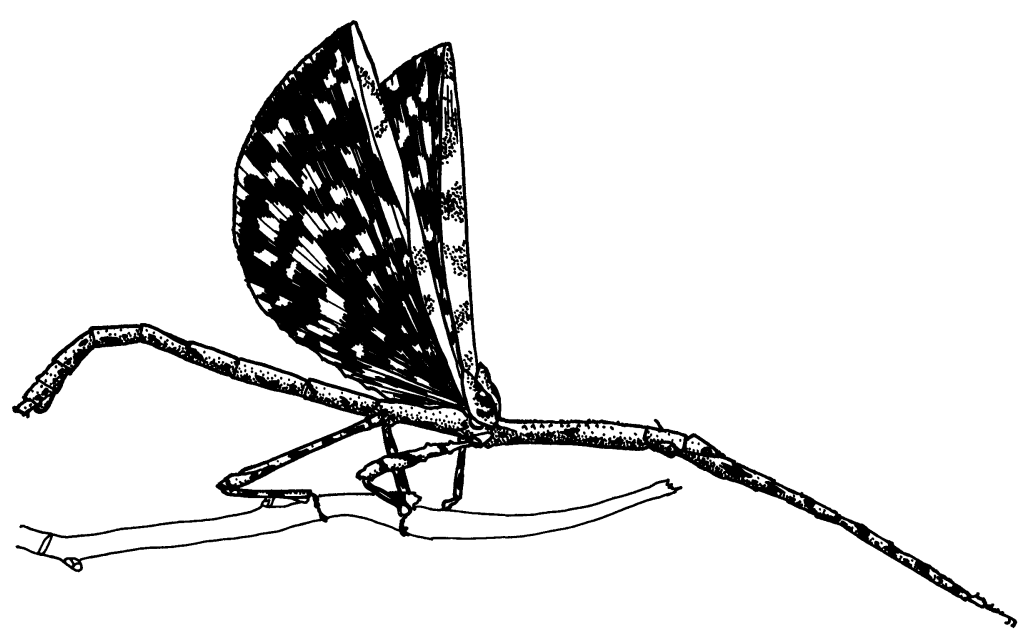

A.

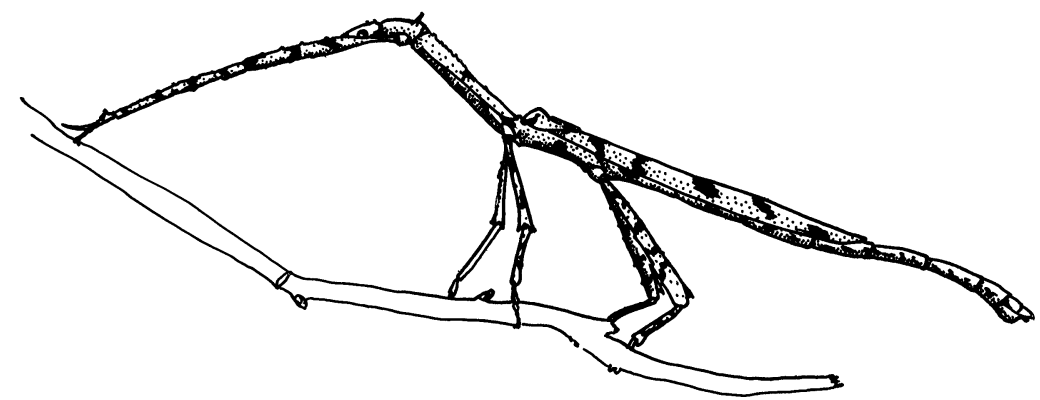

B.

Figure 2. A. Display of male $P$. spinulosus showing vertical wing erection and commencement of body flexure.

B. Bizarre attitude assumed after display by male $P$. spinulosus. (Based on photographs by N. D. E. Smythe).

expanded the wings are moved against the tegmina as shown in Figure 3. This movement enhances the conspicuousness of the display and adds the acoustic component. Wood-Mason (1877) described stridulation in a species of Pterinoxylus (possibly $P$. spinulosus, see Rehn 1957) as occurring when the rasps on the superior surface of the costal area of the wings "are scraped by the sharp and hard front edge of the tegmina". This statement implies, perhaps unintentionally, that the tegmina are the active members. In fact, analysis of movie film of the wing movements suggests strongly 
that the tegmina are moved passively as a consequence of the activities of the wings. Thus when the wings sweep forwards they appear to push against the tegminal margins, causing the tegmina to erect and separate at their apices. The backward movement of the wings is accompanied by a partial lowering of the tegmina and during this their inner margins again become contiguous. When the wings

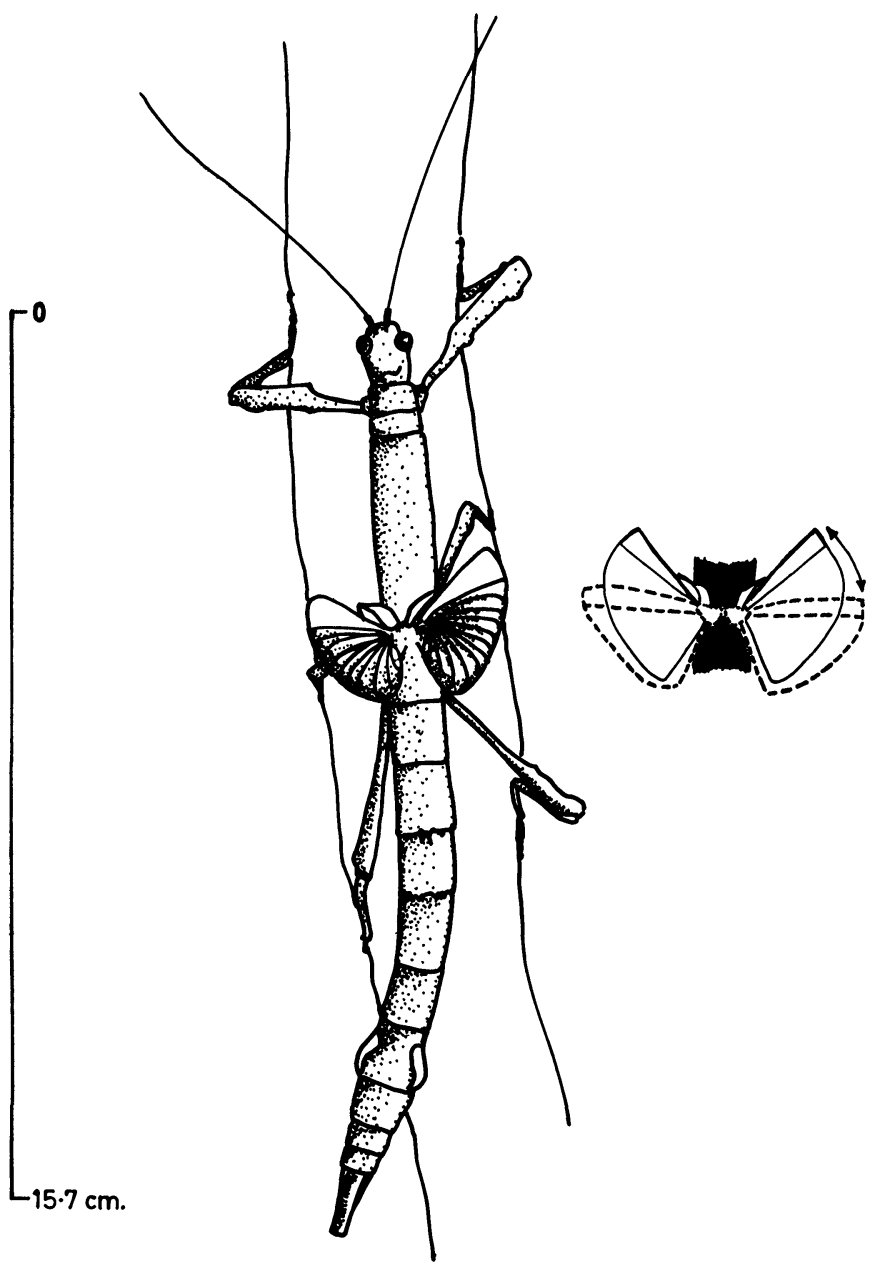

Figure 3. Display of female $P$. spinulosus. Detail (right) shows wing movements (see text). (Based on frames of $16 \mathrm{~mm}$ cine film). 


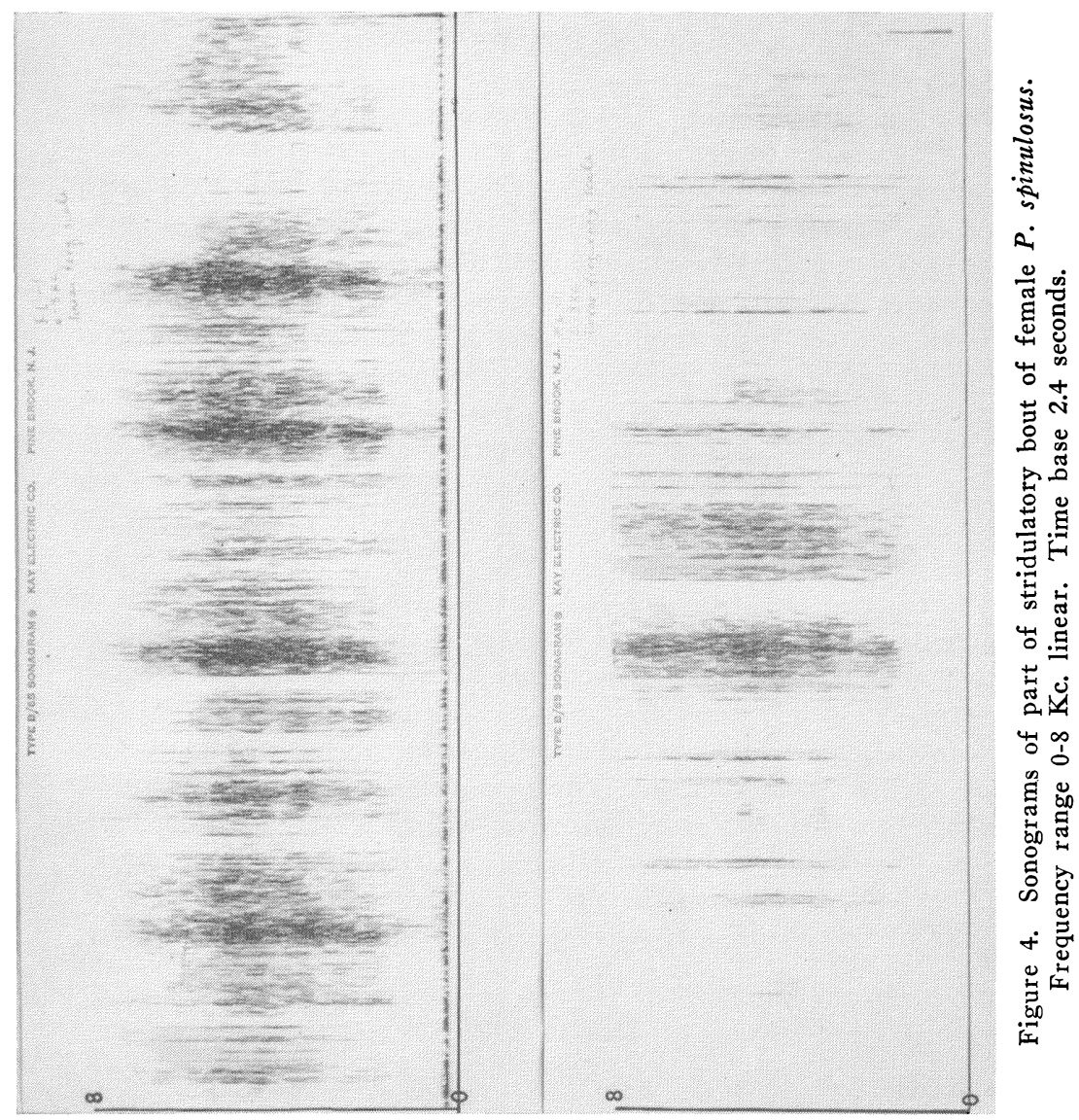


are in the forward position and before the conspicuous backward stroke, there is a period during which the wings appear to be moved against the raised tegmina in a series of short duration, low amplitude thrusts. The extent of movement during these thrusts is so slight as to be barely measurable from film analysis. During display, the membranous area of the wing is not flat but quite clearly curved downwards at the margins so that the wing is convex above and concave below.

Ruud, quoted by Rehn ( 1957 ) described the stridulation as being a noise not unlike that of "a bumble bee or distant airplane". Sounds are extraordinarily difficult to describe in words and it therefore seems useful to include portions of a sonogram of this stridulation (Figure 4). This represents the first and last 2.4 seconds out of a stridulatory bout of over fifteen seconds. The stridulation proves to be an untuned noise without discernable harmonics and with intermittent variations in intensity. The periods of intense noise vary in duration and interval, waning in the former respect towards the end of the display. Both direct observation and analysis of film suggest that the intense sound production, reflected by the dense portions of the sonogram, may occur when the wings are in the forward position described above. The relatively quiet period would then correspond to the periods of backward wing movement when the tegmina are being lowered. This hypothesis could be checked by making a film of the wing movements with a precisely synchronized sound track.

As in the case of the male display, that of the female may be followed by the assumption of a bizarre position similar to that shown in Figure 2 (with the exception of the wings which are folded and concealed). With successive stimulation the tendency to display decreases. Males eventually fly off whilst females walk rapidly away from the disturbance, giving sporadic displays whilst walking.

\section{Discussion}

Consideration of stick mimicry in general and that of phasmids in particular, raises a number of interesting problems. Most insects which are regarded as stick mimics possess morphological features which are incongruous with detailed resemblance to sticks but are necessary for essential biological activities. The walking legs of phasmids are obvious examples. If visually hunting insectivorous predators use typical features of insect organization as cues in prey detection (a possibility which I have developed elsewhere, Robinson, 
in $\operatorname{press}^{\mathrm{a}}$ ), it is reasonable to assume that adaptations will occur which serve to conceal these features. Many stick mimicking phasmids appose the anterior limbs and protract these in line with the long axis of the body. This can be regarded as both concealing limb structure and increasing the apparent length of the body and its resemblance to a tapering stick. In phasmids the protracted limbs enclose the antennae and partially enclose the head, and thus may be regarded as also concealing these features of insect structure. A similar and convergent anterior limb attitude is adopted by some stick mimicking mantids and ploiariids, although in these cases the antennae and head are not concealed.

However, most of the phasmids which adopt a stick attitude at rest stand with the intermediate and posterior legs extended in attitudes similar to those involved in locomotion. The conspicuousness of these legs may be reduced by cryptic coloration and the possession of complex foliaceous processes but they could still be cues which would enable a sophisticated predator to detect the presence of the insect. This view is supported by my work (Robinson, in prep.) with Rufous-naped Tamarins, Saguinus geoffroyi. These small insectivorous primates proved capable of detecting the presence of dead phasmids which had only the intermediate or posterior legs extended, much more rapidly than those which had been arranged in the cataleptic stick position (see below) in which all the legs were concealed. These experiments were conducted with a phasmid Metriotes diocles Westw., which drops from the resting substrate when disturbed and assumes a cataleptic stick attitude after dropping. This attitude involves anterior limb protraction and the apposition of the other limbs to the sides of the body. Similar attitudes are assumed in similar circumstances by other phasmids (see Steiniger 1933) and also by phasmids which rest with the body closely appressed to the substrate (Robinson, in press ${ }^{\mathrm{a}}$ ). The resting attitude of $P$. spinulosus can perhaps be regarded as the functional homologue of such attitudes in so far as it involves concealment of the intermediate and posterior limbs. The $P$. spinulosus resting attitude effects leg concealment whilst permitting a sticklike orientation to the substrate and without impairing the efficiency of the legs as locomotory organs.

Consideration of the presumed startle display also raises a number of questions. The bases for assuming that the display has an antipredator function are its form and the circumstances in which it occurs. In the male it has similar elements to the startle displays of mantids (Crane 1952, Varley 1939) involving sudden apparent increase in size and the revelation of previously concealed bright colors. 
In the females the increase in apparent size is not striking but here there is the significant additional factor of the acoustic component. The form of defensive adaptations in animals must clearly be a compromise between the requirements of defense and those of other, and perhaps conflicting, biologically important activities. In Neotropical phasmids of severai genera (representing several families) the ability to fly may be possessed by both sexes (e.g. Metriotes, Prisopus, Pseudophasma, Isagoras, Stratocles, etc.) or only males (e.g. Pterinoxylus, Bacteria, etc.). Whatever the causes of the tendency towards flightlessness in females, we can ask whether there is a minimum size to which wings can be reduced and still be effective in startle displays. If there is, it is conceivable that some species may evolve towards a compromise between reducing organs no longer serving their primary function and the requirements of their secondary function, and approach this level. Others may add an acoustic component to the display which may reduce the importance of its visual aspects and enable a reduction beyond the level of a purely visual display.

The interpretation of the wing display and stridulation of the female $P$. spinulosus as a startle display is admittedly based on inferences and can only be ultimately resolved by well-designed experiments with predators. However, it is given in circumstances consistent with this interpretation and has not been observed in any other circumstances. It is not given (so far as I can determine) by undisturbed active females at night when it could conceivably occur as a means of attracting males (and enabling males to locate females), and did not occur prior to, during or after the two matings I observed. In these cases the males approached the females and assumed a copulatory position in the mannner I have described for the Oriental phasmid Orxines macklotti De Haan (Robinson 1964). Conspicuous displays by winged phasmids for which an anti-predator function has been claimed (or can be inferred) have been described for seven species representing seven genera. All, with the exception of the female $P$. spinulosus display, involve vertical wing erection. Sound production occurs in the displays of Eurycnema goliath (Gray) and Tropidoderus childrenii (Gray) according to Bedford and Chinnick (1966). These authors attribute the sound production to the raising and lowering of the wings which accompanies movements of the anterior legs. Carpenter ( 1942 ) reports observations by E. Burtt on a similar display by a Palophus species from Tanganyika and Foucher (1916) reported sound production in Cyphocrania 
gigas during a wing erection display. Rehn (1957) gave an incomplete description of the female display in Pterinoxylus spinulosus quoting from the observations of Scholander and Ruud made at Barro Colorado Island. Only in the case of E. goliath were both sexes observed. In this species both sexes have large wings and their display was essentially similar (Bedford and Chinnick, loc. cit.). Orxines macklotti and Metriotes diocles have displays which in both sexes involve vertical wing erection without sound production. The tendency to display in $O$. macklott $i$ is much stronger in females than males whereas the tendency to jump from the substrate in response to tactile stimulation is greater in males. A stridulatory organ on the third antennal joint has been described for the leaf insect Pulchriphyllium crurifolium (Serville), where it is restricted to the female sex (Henry 1924). My own experience with Phyllium bioculatum Gray shows that the female does not use the stridulatory apparatus when disturbed or restrained or in any other context which would suggest that its function was defensive. Thus the display of $P$. spinulosus seems to be unique as far as phasmids are concerned in that although both sexes display the displays differ markedly in form.

Sound production by insects which are attacked, disturbed or restrained by other animals is well known for insects of several orders (see, for instance, Alexander 1960 and Dumortier 1963). There has been considerable discussion about the function of these sounds. In some animals they serve to alert conspecifics but there is no direct proof of a startle function.

A further point of interest with regard to phasmid startle displays is that these, unlike other defensive adaptations in phasmids (with the exception of escape flight) are available only to the adult. So far I have not found any defensive adaptations which are present in the immature stages which are additional to those of the adult and might compensate for the lack of the full adult defensive repertoire. A possible exception to this may be the fact that color changes occur during the first instar of some species (e.g. Phyllium sp.) and at the final ecdysis in others (e.g. Metriotes diocles Westw.) The first of these can be related to the fact that many phasmids hatch on the forest floor where the predominant color may differ markedly from the predominant color of the twigs on their food plant. The second type may be related to a change in the ecology of the animal at maturity. Such a change could render the animal more vulnerable to predation and might explain why the nymphs can survive with 
fewer lines of defense than the adults. In $P$. spinulosus there are no obvious differences between the ecology of the adult females and the nymphs which suggest that there could be any great difference in susceptibility to predation. The size difference between the last nymphal stage and the adults is not striking. It is my general impression that in tropical forests, individual phasmids (of any one species) may be highly dispersed and adult males may, as a consequence, have to search actively over considerable distances for females. Such searching could presumably render males more liable to predation than nymphs or females and might favor the evolution of more lines of defense in this sex. This seems to be true of the wingless phasmid Oncotophasma martini (Griffini) (Robinson, in press $^{\mathrm{b}}$ ). In the case of $P$. spinulosus, males have been caught flying to light at distances of several hundred meters from the nearest food plant. Their retention of the power of flight may provide them with an efficient means of escape not available to the females.

\section{References Cited}

Alexander, Richard D.

1960. Sound communication in Orthoptera and Cicadidae. In Lanyon W. E. and W. N. Tavolga (Eds.), Animal sounds and communication, Institute of Biological Sciences, Washington, D.C., 7: 38-92.

Bedford, G. O. And L. J. Chinnick.

1966. Conspicuous displays in two species of Australian stick insects, Anim. Behav., 14: 518-521.

Carpenter, G. D. H.

1942. Notes by E. Burtt on a species of Palophus (probably episcopalis Kirby), Proc. R. ent. Soc. Lond. A, 17: 75-76.

ChOpard, L.

1938. La biologie des Orthoptères, Encyclopédie Entomologique, 20, Crane, J. Paul Lechevalier, Paris.

1952. A comparative study of innate defensive behavior in Trinidad mantids (Orthoptera, Mantoidea), Zoologica, N.Y., 37: 259-293. DUMORTIER, B.

1963. Ethological and physiological study of sound emissions in Arthropoda, In R. G. Busnel (Ed.) Acoustic behavior of animals, FOUChER, G. Elsevier Publishing Company, N.Y.

1916. Etudes biologiques sur quelque Orthoptères. Bull. Soc. natn. Acclim. Fr., 63: 263-273.

Henry, G. M.

1924. Stridulation in the Leaf-Insect, Spoilia zeylan, 12: 217. 
REDTENBACher, J.

1908. In Brunner v. Wattenwyl and J. Redtenbacher, Die Insektenfamilie der Phasmiden. Leipzig.

REHN, J. A. G.

1957. The description of the female sex of Pterinoxylus spinulosus, with notes on stridulation in the female sex of this genus (Orthoptera; Phasmatidae, Phibalosomatinae), Trans. Amer. ent. Soc., 83: 185-194.

Robinson, M. H.

1964. The Javanese stick insect Orxines macklotti De Haan (Phasmatodea, Phasmidae), Entomologist's mon. Mag., 100: 253-259.

1968. The defensive behaviour of the Javanese stick insect Orxines macklotti De Haan (Phasmatodea, Phasmidae), Entomologist's mon. Mag. 104.

in pressa. Defenses against visually-hunting predators.

in press ${ }^{b}$. The defensive behaviour of the Panama stick insect OncotoSTEINIGER, F. phasma martini (Griffini); (Phasmatodea, Phasmidae).

1933. Die Erscheinungen der Katalepsie bei Stabheuschrecke and Wasserläufern. Z. Morph. Ökol. Tiere. 26: 591-708.

VARLEY, C. G.

1939. Frightening attitudes and floral simulation in praying mantids. Proc. R. ent. Soc. Lond. 14: 91-96.

Wood-Mason, J.

1877. Report of the Society's meeting held on Nov. 7 th, 1877. Trans. ent. Soc. Lond., Page 28. 

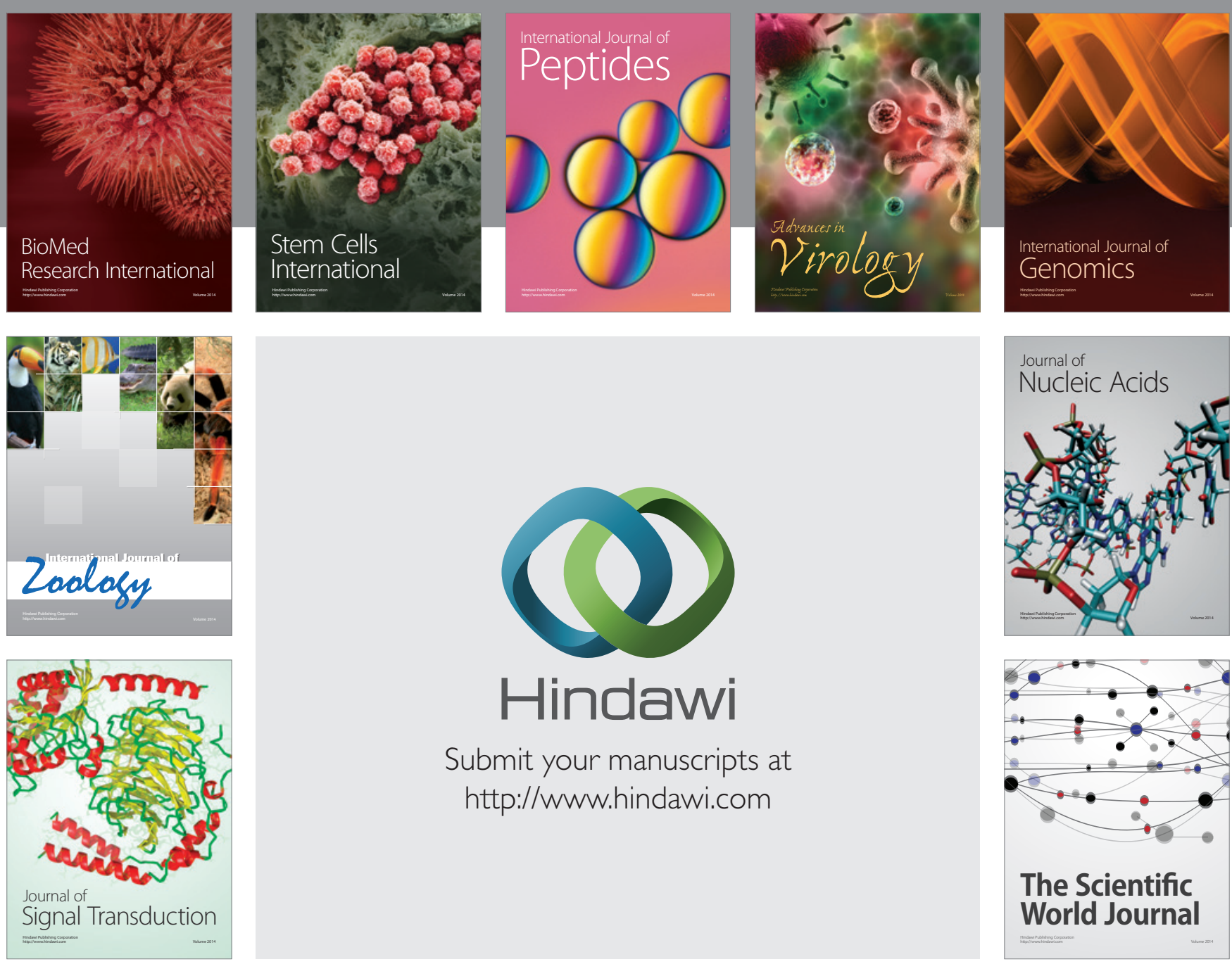

Submit your manuscripts at

http://www.hindawi.com
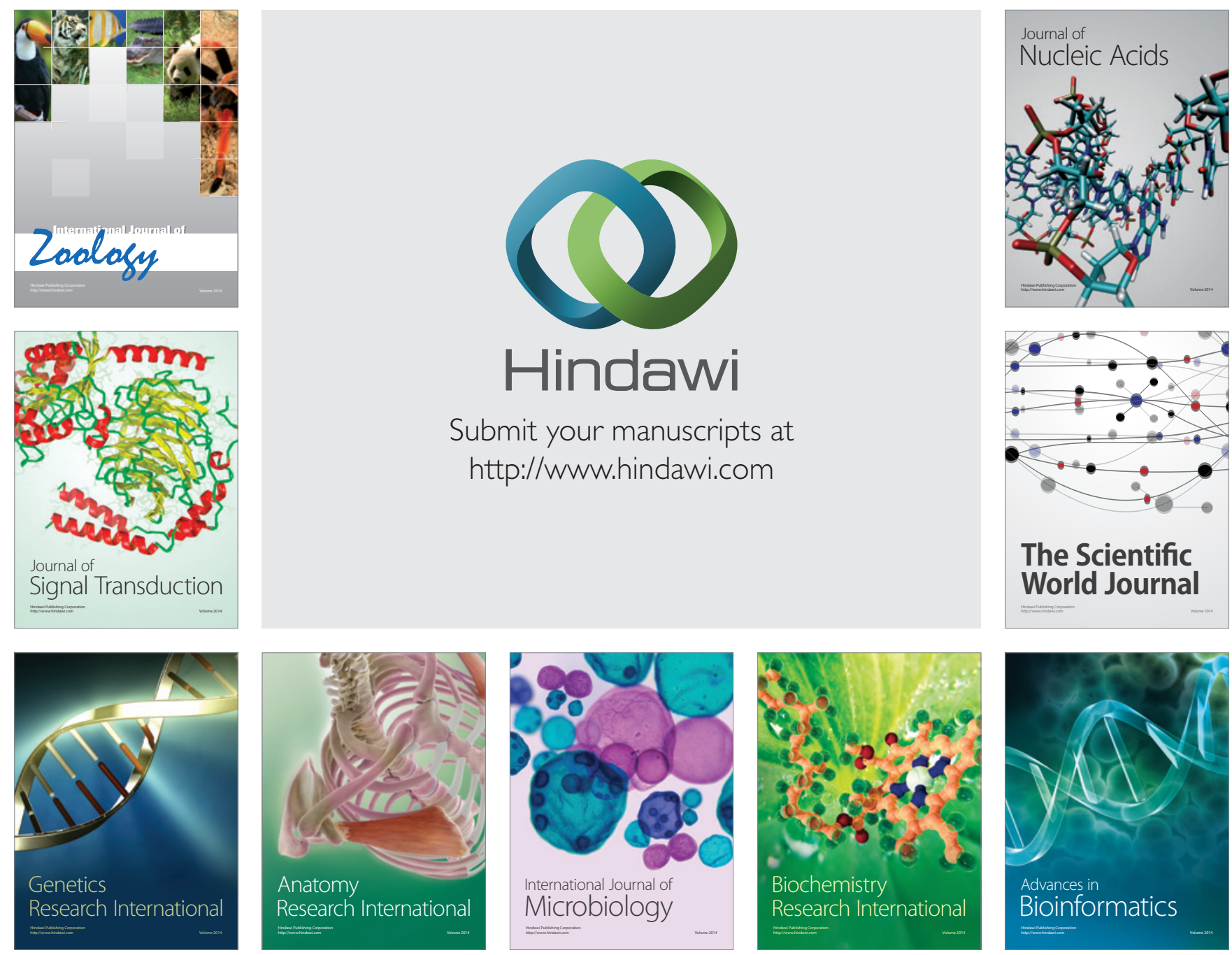

The Scientific World Journal
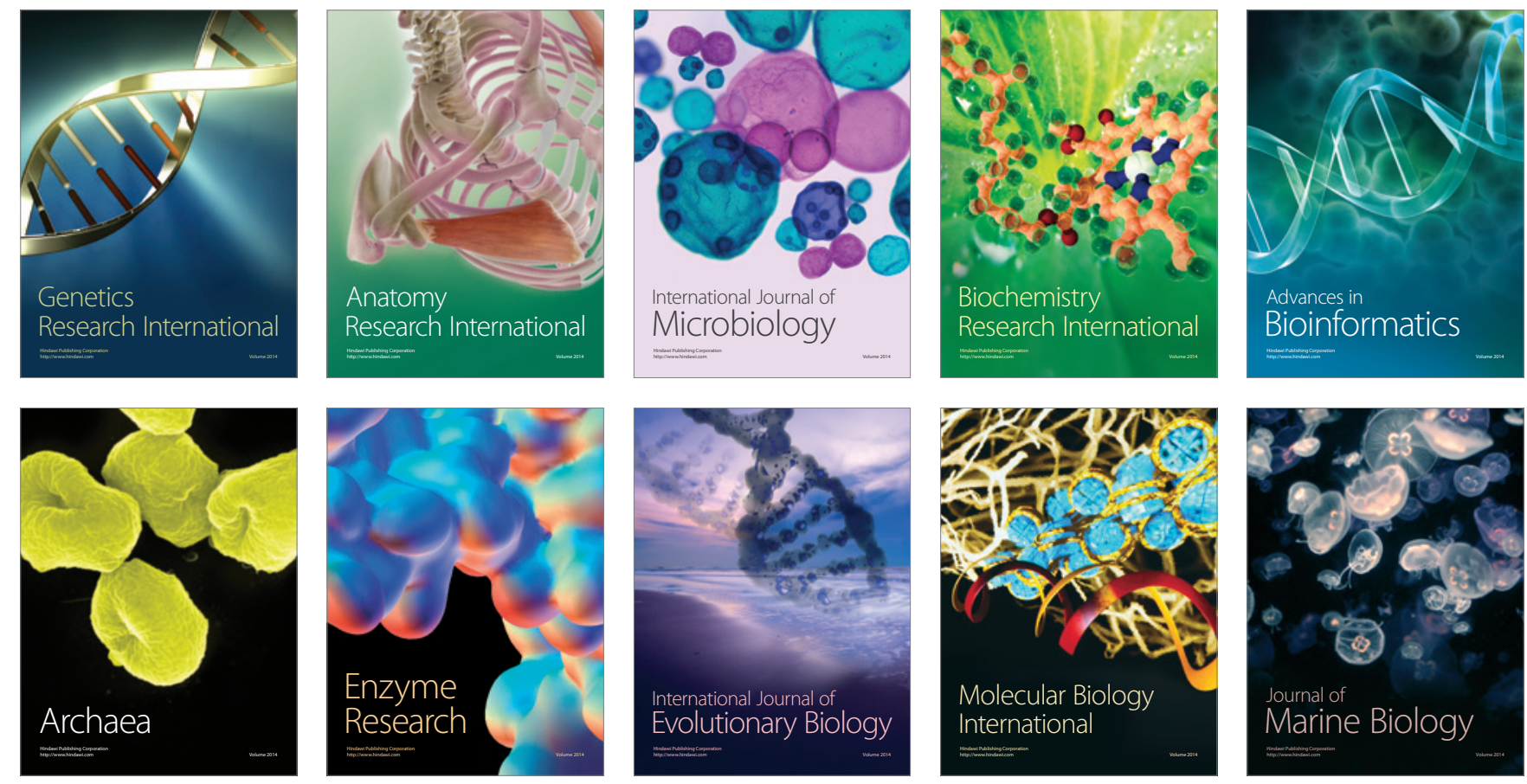